\title{
REFLEXÕES SOBRE GESTALT-TERAPIA E PSICODRAMA A PARTIR DO MOVIMENTO DE INTEGRAÇÃO EM PSICOTERAPIA
}

\author{
Reflections on Gestalt Therapy and Psychodrama from the Movement of Integration of \\ Psychotherapy
}

Reflexiones sobre la Terapía Gestalt y el Psicodrama a partir del Movimiento de Integración en Psicoterapia

ÉRICO DOUGLas VieIRA

LUC VANDENBERGHE

\begin{abstract}
Resumo: Este artigo apresenta algumas reflexões sobre a possibilidade de um diálogo entre a Gestalt-Terapia e o Psicodrama. O Movimento de Integração em Psicoterapia sugere que nenhuma abordagem em psicoterapia alcança o esgotamento da compreensão do ser humano em sua complexidade. Porém cada abordagem possui sua filosofia e sua visão da natureza do sofrimento e da cura. Esse fato dificulta o diálogo e as trocas com as escolas concorrentes e as tentativas de integração podem esbarrar num ecletismo superficial. Assinalamos que a Gestalt-Terapia e o Psicodrama compartilham uma visão antropológica fenomenológico-existencial, podendo este parentesco subsidiar um diálogo verdadeiro. Além disso, existe uma proximidade entre os estilos clínicos das duas escolas, por ambas enfatizarem as dimensões da ação e do experienciar. Por fim, argumentamos que ao compreender melhor a outra orientação, tanto o Gestalt-Terapeuta quanto o Psicodramatista podem aumentar sua apreciação do processo psicoterápico e crescerem como terapeuta. Além desse benefício individual, cogitamos que as próprias escolas de psicoterapia podem amadurecer pelo contato com as ideias da outra. Uma consideração aberta e não dogmática de conceitos e técnicas - ora conciliáveis, ora complementares, ora antagônicos - facilitaria aos supervisores, docentes, clínicos e pesquisadores questionarem e aprofundarem seu próprio modelo clínico.
\end{abstract}

Palavras-chave: Gestalt-Terapia; Psicodrama; Integração em Psicoterapia.

Abstract: The present article presents reflections on the possibility of a dialogue between Gestalt-Therapy and Psychodrama. The Psychotherapy Integration Movement suggests that no single psychotherapy can arrive at a complete comprehension of the person in his or her complexity. However, every approach to psychotherapy has its philosophy and its look at the nature of suffering and cure. This hinders the dialogue and the exchanges with competing schools. As a result, integration may not go further than superficial eclecticism. We remark that Gestalt Therapy and Psychodrama share a phenomenological-existentialist outlook. And this common trait may aid a true dialogue. Besides, there is a similarity between the clinical styles of both schools, because both underline the dimensions of action and experience. In conclusion, we argue that, by understanding better the other approach, both the Gestalt Therapist and the Psychodramatist can increase their appreciation of the psychotherapy process and grow as therapists. Besides this personal benefit, we believe that the schools of psychotherapy in themselves may become more mature through the contact with the ideas of the other. An open, not dogmatic consideration of concepts and techniques - at times compatible, at others complementary or even opposed - aids supervisors, teachers, clinicians and researchers to question and deepen their own clinical model.

Keywords: Gestalt Therapy; Psychodrama; Integration of Psychotherapy.

Resumen: Este artículo presenta algunas reflexiones sobre la posibilidad de un diálogo entre la Terapia Gestalt y psicodrama. El Movimiento de Integración en Psicoterapia sugiere que un enfoque único a la psicoterapia llega el agotamiento de la comprensión humana en su complejidad. Sin embargo, cada método tiene su propia filosofía y su visión de la naturaleza del sufrimiento y la curación. Este hecho complica el diálogo y los intercambios con las escuelas que compiten y los esfuerzos de integración puede resultar en un eclecticismo superficial. Tomamos nota de que la Terapia Gestalt y Psicodrama compartir una visión antropológica-existencial fenomenológica, esta relación se puede subsidiar a un verdadero diálogo. Además, hay similitudes entre los dos estilos de las escuelas clínicas, ambos destacan las dimensiones de la acción y la experiencia. Finalmente, se argumenta que para entender la otra dirección, tanto como el psicodramatista y terapeuta Gestalt pueden aumentar su comprensión del proceso psicoterapéutico y crecer como terapeuta. Además de este beneficio individual, la teoría de que las escuelas de psicoterapia puede madurar por el contacto con las ideas de otro. Una mente abierta y no dogmática los conceptos y técnicas - ahora reconciliados, a veces complementarias, a veces antagónicas - facilitar a los supervisores, profesores, psicólogos clínicos e investigadores cuestionar y profundizar su modelo de clínica propia.

Palabras-clave: Terapía Gestalt; Psicodrama; Integración en las Psicoterapías. 


\section{Introdução}

Este artigo pretende discutir as possibilidades de integração entre conceitos, técnicas e práticas do Psicodrama e da Gestalt-Terapia. Parte-se do pressuposto de que talvez estas abordagens possuam certa compatibilidade de conceitos e pressupostos filosóficos em comum e que poderia ser fecunda tal integração.

Em um primeiro momento, faremos uma exposição sobre alguns aspectos do movimento de integração em psicoterapia. Este movimento origina-se nos Estados Unidos e tem manifestações na Europa. No caso do Brasil, existem poucas discussões de âmbito coletivo sobre o assunto; decorrente disto parece importante nos deter em descrever um panorama geral sobre o movimento de integração em psicoterapia. Em uma segunda etapa, faremos algumas aproximações entre aspectos do Psicodrama e da Gestalt-Terapia, propondo algumas possibilidades de integração.

Em seguida, oferecemos uma descrição de alguns aspectos importantes do movimento de integração em psicoterapia, passando brevemente pela história da psicologia clínica.

\section{O Movimento de Integração em Psicoterapia}

\subsection{Aspectos Históricos}

Hawkins e Nestoros (1997) remontam à antiguidade grega os primórdios dos sistemas psicoterápicos. Propõem o nome do filósofo Sócrates como o fundador da psicoterapia, com a elaboração do método socrático, que sucintamente consistia em ajudar o interlocutor a encontrar soluções para seus próprios problemas. Pode-se dizer que alguns dos sistemas em psicoterapia atuais, notadamente as vertentes clínicas humanistas, utilizam-se da ideia de que é mais desejável que o próprio paciente encontre as respostas para seus dilemas existenciais. Esta atitude clínica baseia-se em um pressuposto filosófico humanista que entende o homem como centro, como tendo capacidade de se autogerir (Ribeiro, 1985).

Moreira, Romagnoli \& Neves (2007) discutem o surgimento da psicologia clínica argumentando que existe uma estreita ligação desta disciplina com a clínica médica, apontando Freud como o pai da psicologia clínica. Originalmente a atividade clínica (do grego kliné) consistia no exame realizado pelo médico à cabeceira do doente para fins de diagnóstico, prognóstico e prescrição de um tratamento. Este exame era feito no domicílio do doente utilizando-se de observações e entrevistas. Hipócrates, há 2500 anos, inaugura a observação clínica criando a anamnese como primeira etapa do tratamento. As palavras tratamento, diagnóstico e anamnese, por exemplo, ainda são utilizadas pelos psicoterapeutas atualmente, o que nos leva a perceber a influência do discurso médico na clínica psicológica. Freud ao criar a psicanálise, subverte alguns aspectos do modelo médico. Muda o paradigma da observação para o da escuta e coloca o discurso e o saber do paciente no centro da cena do tratamento. Além disso, o paciente passa a ser visto como o sujeito da história do seu adoecimento e não mais como mero objeto. Mesmo com algumas rupturas importantes realizadas por Freud, podemos dizer, de acordo com Moreira, Romagnoli \& Neves (2007), que a clínica psicológica herda questões importantes do modelo médico - observar e diagnosticar para depois intervir, tratar e curar.

Podemos mapear três correntes principais em psicoterapia que foram se estabelecendo no século XX, seguindo as ideias de Hawkins \& Nestoros (1997): (1) As abordagens psicodinâmicas que enfatizam a importância dos conflitos inconscientes. (2) As abordagens comportamentais que entendem os comportamentos funcionais e disfuncionais como produtos de aprendizagem. (3) As abordagens humanistas/existenciais/fenomenológicas que enfatizam a liberdade de escolha.

Hawkins \& Nestoros (1997) situam os primórdios do chamado movimento integracionista na década de 1930. Na reunião anual da American Psychiatric Association de 1932, Thomas French tentou demonstrar a similaridade entre o conceito freudiano de repressão e os conceitos pavlovianos de extinção e inibição (Hawkins \& Nestoros, 1997). Tratava-se de uma verdadeira tentativa de integração teórica, pois, se os conceitos comportamentais podiam ser traduzidos diretamente para a psicanálise e vice-versa, os aportes de cada teoria poderiam ser aproveitados para enriquecer, corrigir ou aprofundar a outra abordagem. No entanto, durante a maior parte do século XX, predominava entre clínicos a convicção de que os seus próprios sistemas forneciam suficiente sustento teórico e tratamento dos problemas psicológicos. O diálogo era desnecessário a não ser para convencer o outro do seu erro.

Só cinqüenta anos depois do discurso de French, Goldfried (1982) propôs uma integração entre as terapias comportamental e psicodinâmica; e Kohlenberg \& Tsai (1987) iniciaram suas publicações sobre uma psicoterapia de base behaviorista, baseada exclusivamente no poder curativo de um relacionamento intenso e genuíno entre terapeuta e cliente. Logo, Steven Hayes formulou uma terapia comportamental pautada nos valores mais profundos do cliente, no abandono da luta contra o sintoma, como também na desconstrução dos processos sócio-linguísticos subjacente ao do sofrimento subjetivo (Eifert \& Forsyth, 2005). Tais propostas foram possíveis graças a um questionamento do paradigma comportamental em confronto com as visões clínicas psicodinâmica e humanista, acarretando uma nova leitura do próprio paradigma. Esta gerou uma reinterpretação dos seus axiomas, uma visão enriquecida do ser humano e do processo terapêutico. 
Enquanto as propostas acima mencionadas originaram-se num amadurecimento teórico surgindo do diálogo de uma abordagem com outras, emergiu uma segunda forma de intercâmbio entre as psicoterapias, que não exige uma reflexão crítica sobre a própria teoria. Trata-se do ecletismo técnico, proposto em 1967 por Lazarus. Esse autor afirmava ser possível utilizar técnicas provenientes de diferentes sistemas terapêuticos sem uma consideração maior dos insights teóricos ou filosóficos associados a estes métodos. Tentou divulgar o ecletismo técnico durante toda a década de setenta, mas esbarrou na crítica que a psicoterapia perde em profundidade quando desvincula a técnica da visão teórica e epistêmica que a gerou (Hawkins \& Nestoros, 1997). Uma terceira tendência ganhou importância somente no fim do século passado. Consiste na procura de processos comuns que estariam envolvidos em todas as psicoterapias eficazes, independente das explicações teóricas que cada abordagem propõe (Norcross, 2010). Entre os três, a última orientação possui o aspecto mais ameaçador, porque sugere que os resultados obtidos com os diferentes tratamentos não são devidos aos conceitos propostas pelas teorias.

Recentemente, ocorreu uma abertura crescente para as três formas de integração, que contribui para o florescimento de publicações e para a criação de duas organizações que discutem o tema: a SEPI (Society for the Exploration of Psychotherapy Integration) e o IAEP (International Academy of Ecletic Psychotherapists). Atualmente temos o Journal of Psychotherapy Integration da APA (American Psychological Association) como um importante canal de discussões e apresentações de ideais do movimento integracionista.

Precisa-se observar que a história do o movimento integracionista ocorreu nos EUA. No caso brasileiro, parece ainda não haver espaço e popularidade para esta discussão. Resta-nos saber as razões da falta de interesse nesta discussão. Podemos nos perguntar se as condições para o surgimento do movimento integracionista estão presentes no Brasil.

\subsection{Condições para o Surgimento do Movimento Inte- gracionista}

Dentre as condições para o surgimento dos esforços integrativos, Hawkins \& Nestoros (1997) apontam as seguintes: proliferação das terapias, percepção das limitações das abordagens, igualdade de resultados entre diferentes tratamentos, convergências nas psicoterapias, semelhanças entre os tratamentos e a natureza complementar das diversas orientações.

A fragmentação decorrente do aparecimento de novas orientações em psicoterapia se associou a pressões de consumidores exigindo qualidade, o que motiva os clínicos a tentarem desenvolver sistemas mais eficazes de psicoterapia. De acordo com Hawkins \& Nestoros
(1997), existem mais de quatrocentos sistemas de psicoterapia. Esta proliferação de psicoterapias torna difícil sustentar que só uma delas possua a verdade e as outras não têm validade. É um dos grandes motivos apontados para o interesse crescente em integração de psicoterapias (Goldfried, 1982).

Em certos meios de psicoterapeutas estadunidenses cresceu a opinião que a própria abordagem adotada é insuficiente para lidar com todas as diferentes realidades clínicas. Essa opinião foi sustentada na medida em que cada paciente tem necessidades diferentes e o fenômeno psicológico é sempre mais complexo do que os conceitos descritos numa única abordagem (Hawkins \& Nestoros, 1997).

Os estudos empíricos que se acumularem durante décadas de pesquisa sobre a eficácia das psicoterapias trouxeram uma conclusão desconcertante. Apesar de sugerir que certa técnica ou atitude terapêutica pode ser mais eficaz para certo problema ou certo tipo de paciente, muitas abordagens diferentes possuam efeitos positivos. As pesquisas mostram que não existe uma abordagem superior a todas as outras. E para certos problemas, os resultados tendem a ser semelhantes, independentemente da abordagem adotada (Rogers, 1982; Norcross, 2010).

A convergência das terapias (Hawkins \& Nestoros, 1997) é um conceito que se refere à observação de que os psicoterapeutas individuais se tornam mais semelhantes com experiência acumulada, além da ideia de que diferentes abordagens tornam-se mais semelhantes à medida que se desenvolvem e amadurecem. Como exemplo: algumas vertentes psicanalistas tentam levar em consideração a realidade externa e aspectos interpessoais no tratamento. Seria um processo evolutivo no qual os sistemas em psicoterapia vão progressivamente incorporando e assimilando aspectos da realidade clínica, antes negligenciados (Hawkins \& Nestoros, 1997). Gradualmente desenvolvemse fatores comuns presentes em qualquer relação terapêutica (Sommers-Flanagan, 2006; Norcross, 2010).

Por fim, há uma percepção cada vez mais freqüente de que as abordagens possuem naturezas complementares. A idéia é que sistemas diferentes podem ser combinados e o resultado seria um produto mais rico (Hawkins \& Nestoros, 1997). No geral os sistemas em psicoterapia sempre enfatizam um determinado aspecto como o insight, o comportamento, os sentimentos. Se partirmos do pressuposto de que todos estes aspectos são importantes, então podemos entender que a força de determinada abordagem pode contribuir para complementar a outra.

\subsection{Diversidade e Polêmica na Integração de Psicote- rapias}

Caso o psicoterapeuta brasileiro concorde que ao menos algumas das condições acima elencadas se apresentam no cenário nacional, ainda é necessário se fa- 
zer uma escolha entre as diferentes formas de diálogo entre as abordagens. Essa escolha é importante porque as diferentes vias oferecidas diferem tanto nas suas implicações epistêmicas quanto nas opções clínicas a serem feitas.

No ecletismo técnico, o psicoterapeuta mantém sua abordagem teórica. Apenas seleciona técnicas de outras abordagens sem aderir às bases teóricas associadas a estes métodos. A preocupação é tecnológica e não teórica, ou seja, selecionar as técnicas que são mais úteis para determinado problema ou tipo de cliente, sem precisar refletir sobre a teoria (Strieker, 1996).

Existe outra corrente de pesquisadores que se interessa nos fatores que as diferentes psicoterapias possuem em comum. O intuito destes pesquisadores é identificar o que realmente funciona para a criação de tratamentos mais parcimoniosos e eficazes (Strieker, 1996; Gonçalves \& Welling, 2001). Tais pesquisas tendam a sugerir que muitas vezes os conceitos usados pelo terapeuta não explicam porque a terapia funciona. Todos os modelos teóricos de psicoterapia deveriam ser revisados para enfatizar os fatores comuns como por exemplo: a relação terapêutica, o apoio emocional, a disponibilização de novos contextos narrativos, o ensaio e enfrentamento, e o desenvolvimento de autonomia (Hawkins \& Nestoros, 1997).

Há muito apoio empírico para a importância da relação terapêutica. O fato de o cliente poder falar com alguém sem ser julgado e a capacidade do terapeuta de suportar estados afetivos desagradáveis parecem cruciais para o sucesso do processo psicoterápico. Psicoterapias eficazes proporcionam contextos narrativos ao cliente que lhe permitem uma compreensão nova de si mesmo e dos outros além de uma ressignificação de várias situações passadas ou presentes. Pelo ensaio e o enfrentamento do problema as questões tratadas na psicoterapia contribuem para que o cliente aprenda a lidar com os problemas reais de sua vida. Neste sentido, uma psicoterapia bem sucedida requer que o paciente coloque em prática as reflexões realizadas no espaço clinico. Por fim, se o cliente pode contar com seu terapeuta no início é bem provável que ele conseguirá ser independente ao final do processo (Hawkins \& Nestoros, 1997).

Um caminho intermediário entre o ecletismo técnico e o movimento dos fatores comuns é a integração teórica que envolve o compromisso de uma criação conceitual ou teórica. O objetivo é criar um quadro conceitual que sintetiza os melhores elementos de duas ou mais abordagens (Strieker, 1996; Sommers-Flanagan, 2006). Essa integração precisa ser feito com cuidado. Não se pode integrar modelos com pontos de vistas filosóficos incompatíveis (Hawkins \& Nestoros, 1997). Para nosso trabalho este ponto não causaria grandes problemas porque o Psicodrama e a Gestalt-Terapia têm perspectivas filosóficas e teóricas em comum. Compartilham alguns conceitos existencialistas e valorizam muito as dimensões da vivência e da ação, conforme veremos adiante.

\subsection{Exemplos de Integração Teórica}

Sommers-Flanagan (2006) cita algumas abordagens provenientes de esforços integrativos. Cita entre outros, a Terapia Comportamental Dialética que combina práticas cognitivo-comportamentais com elementos das abordagens centrada na pessoa, gestáltica, psicodinâmica, estratégica e paradoxal. A TCD foi desenvolvida para pacientes emocionalmente instáveis com uma personalidade dramática, comportamentos autodestrutivos e com tendência suicida que precisam de uma abordagem terapêutica particularmente rica e flexível.

Ainda teríamos a Psicoterapia Cognitivo-Construtivista que integra conceitos psicanaliticos e rogerianos com uma base cognitivo-comportamental. Estas integrações teóricas têm um futuro promissor no âmbito das psicoterapias, na medida em que "uma única teoria não consegue responder ao mundo real com suas diferentes exigências e necessidades" (Sommers-Flanagan, 2006, p. 294).

Outro exemplo de integração teórica, apoiado por similaridades entre as perspectivas das duas abordagens envolvidas, é o esforço de Levy (2000) para integrar conceitos e práticas do Psicodrama e da Psicanálise. A autora argumenta que os psicodramatistas trabalham com o mesmo material intrapsíquico que são estudados pelos psicanalistas. Da mesma forma, psicanalistas atualmente não mais ignoram o mundo externo do sujeito e dão valor às questões interpessoais que são próximos ao trabalho do psicodramatista. O que se conclui é que estas duas abordagens, que tinham, em seus primórdios, pressupostos filosóficos muito diferentes, evoluíram, devido às suas recentes mudanças para perspectivas compatíveis.

A autora supracitada defende a idéia da integração desde que o terapeuta tenha um domínio das técnicas e teorias que utiliza. Desta forma, o terapeuta teria mais flexibilidade para trabalhar e o cliente se beneficiaria com uma abordagem mais atualizada para suas questões. Diz a autora:

O fundamental é nos preocuparmos com a eficácia de nossas terapias, deixando de lado antigas rixas teóricas e/ou filosóficas e caminhando em prol da ciência e do paciente, permitindo-nos então integrar não como tentativa de tornar todos iguais, mas sim de acoplar diferenças para um trabalho terapêutico mais rico, criativo e espontâneo em termos de opções teóricas e clínicas (Levy, 2000, p. 182).

Na história do Psicodrama percebem-se outros esforços integrativos como o Psicodrama Analítico na França que seria a utilização do referencial teórico da Psicanálise aliado às técnicas do Psicodrama. O Psicodrama Triádico utiliza-se dos conceitos da Psicanálise, Dinâmica de Grupo e Psicodrama (Moreno, 1975). Temos, também, a proposta do Sociodrama Familiar Sistêmico realizada 
por Seixas (1992), que integra conceitos do pensamento sistêmico e do Psicodrama no trabalho terapêutico com famílias.

Em relação à Gestalt-Terapia percebe-se, no enfoque de muitos gestaltistas brasileiros, a utilização da Fenomenologia como base epistêmica da Gestalt-Terapia (Ribeiro, 1985; Rodrigues, 2000). É importante assinalar que a Gestalt-Terapia não tinha uma ligação explícita com a Fenomenologia nas formulações iniciais de Frederick Perls. Podemos então dizer que o casamento entre as formulações originais do fundador com a visão fenomenológica, já é um primeiro exemplo bem-sucedido de integração na área da Gestalt-Terapia.

\subsection{Obstáculos à Integração}

Na integração teórica, o intuito é quebrar o dogmatismo presente na adoção da pureza ideológica para aumentar a eficácia em benefício dos clientes em psicoterapia. Por trás do discurso a favor da pureza ideológica pode existir um forte sentimento de lealdade decorrente da manutenção do apego pessoal a determinados conceitos e técnicas terapêuticas. Pode até tratar-se puramente de uma admiração para certo autor. Esta lealdade pode levar a rixas metodológicas repletas de desqualificações e críticas em relação a outras abordagens supostamente concorrentes. Tais embates servem como defesa rígida de pontos de vista, tornando-se secundária a preocupação com a eficácia terapêutica.

Alguns psicoterapeutas possuem um forte compromisso ideológico com sua abordagem de formação, com a construção da crença de que somente sua abordagem é valida. Em decorrência desta espécie de dogmatismo, não estão abertos a conhecerem aspectos de outros sistemas. A lógica da competição prevalece numa sociedade que estimula a concorrência (Hawkins \& Nestoros, 1997).

Um obstáculo que deve ser levado a serio é a existência de diferenças filosóficas entre as abordagens. Os sistemas de psicoterapia possuem princípios diferentes no que diz respeito à natureza humana, aos determinantes no desenvolvimento da personalidade, aos processos de mudança. Por outro lado, os integracionistas alegam que os pontos divergentes é que podem fazer uma valiosa integração reunindo elementos complementares das abordagens (Hawkins \& Nestoros, 1997).

Porém, as diferenças filosóficas podem parecer maiores do que são. Uma falta de linguagem comum entre os psicoterapeutas pode criar a ilusão de incompatibilidade teórica enquanto em realidade se trata de diferenças em terminologia. Um estabelecimento de uma linguagem em comum facilitaria a comunicação, compreensão e a pesquisa. As linguagens isoladas fazem com que os adeptos de determinada abordagem não consigam sair de dentro dos seus "casulos" e também não permitam a entrada de outros.

\section{Aproximações entre o Psicodrama e a Gestalt- Terapia}

O Psicodrama e a Gestalt-Terapia possuem bases epistemológicas em comum. Os integrantes contemporâneas dessas abordagens têm uma visão de ser humano fortemente influenciadas pela Fenomenologia, pelo Existencialismo e pelo movimento Humanista. Almeida (2006), importante psicodramatista brasileiro, afirma que a Gestalt-Terapia apresenta propostas co-irmãs às do Psicodrama. Este autor situa o Psicodrama como um método fenomenológico-existencial sendo este entendido como "o exame ou estudo da experiência não influenciado por conceitos ou preconceitos" (p. 19). Ribeiro (1985) aponta que existem numerosas correntes humanistas, existenciais e fenomenológicas que caminham paralelas "à procura de um lugar comum" (p. 27). Devido à complexidade de cada uma, elas não convergem, mas operam em bases semelhantes como o Psicodrama e a GestaltTerapia, por exemplo.

Moreno (1983) coloca o Psicodrama como uma aplicação de princípios fenomenológicos e existenciais em psicoterapia: "Cada sessão psicodramática é uma experiência existencial e pode fornecer informações fundamentais para uma sólida teoria da existência" (p. 231). Há uma tentativa de integração entre validade científica e validade existencial, ou seja, que as experiências clínicas fossem válidas existencialmente para os clientes e que também pudessem ser objetivadas para análise científica. Moreno tinha a preocupação em estudar a relação objetividade/subjetividade na compreensão da experiência humana, tarefa na qual também se debruçou Husserl com a sua Fenomenologia (Almeida, 2006). A concretização de estados subjetivos nas dramatizações pode aqui ser inserida como uma tentativa de objetivar a subjetividade (Vieira, 2009).

A relação entre as idéias fenomenológicas e existenciais e a Gestalt-Terapia é abordada por Miller (1997) que situa a Gestalt-Terapia como fenomenologia aplicada. Rodrigues (2000) aponta as atitudes fenomenológicas do trabalho gestáltico no enfoque do presente ou aqui-eagora na prática da psicoterapia. Interessa o que o cliente traz e o que ele vive naquele momento, pedindo-se que este descreva seus pensamentos e sentimentos presentes. Como influência marcadamente existencial, está a ideia de ser-no-mundo como coloca o autor: "o ser humano está inserido no mundo, está sempre em relação com o mundo e o mundo está sempre reagindo a ele" (Rodrigues, 2000, p. 54). Decorre daí a noção de que a Gestalt-Terapia, assim também como o Psicodrama, é abordagens relacionais, pois interessam a elas o ser humano em relação no seu contexto.

Propomos, acompanhados por Almeida (2006), que as duas abordagens podem ser consideradas como métodos fenomenológico-existenciais ou como psicoterapias de base fenomenológico-existenciais. O principal expoen- 
te da Fenomenologia foi Edmund Husserl que pretendia voltar-se para as coisas em si mesmas ao invés de invocar teorias que o afastassem da verdade. A Fenomenologia surge como método que pretende estudar a realidade que se mostra, ou seja, o fenômeno (Rodrigues, 2000). É um esforço de voltar às coisas mesmas e um encontro com a realidade, tal qual se apresenta a nós. Para isto, é preciso que a realidade seja percebida antes de todo conhecimento, não se deixando contaminar por este (Ribeiro, 1985).

Husserl interessou-se pelos processos pelos quais a consciência percebe a realidade. Teríamos a intencionalidade na qual o sujeito se abre para o mundo, buscando um sentido. A consciência apreende o mundo ativamente, sendo impossível separar a consciência do mundo, sendo interessante observar como o mundo se manifesta na consciência (Almeida, 2006). Busca-se a intuição como uma forma de apreensão clara e correta da verdade, anterior aos preconceitos e reflexões. A redução fenomenológica ou epoché é a tentativa de suspensão temporária dos juízos, noções preconcebidas e aprioris que temos sobre o objeto observado (Rodrigues, 2000). É importante dizer que a redução completa é impossível de ser alcançada, mas o exercício de suspensão temporária das preconcepções representa algo que permite a emergência do fenômeno. De qualquer maneira, a postura do gestaltterapeuta deve ser a de abertura à realidade que se apresenta, suspendendo os juízos (Ribeiro, 1985).

De acordo com Almeida (2006) a Fenomenologia de Husserl e as filosofias da existência se unem no entendimento do princípio da intersubjetividade. Retomando o princípio da intencionalidade, dizemos que a consciência visa sempre um objeto, e este pode ser também outra consciência. Esta outra consciência também tem uma intencionalidade, podendo-se dizer que "cada um é sujeito e objeto em relação ao outro” (p. 37). Neste princípio da intersubjetividade percebemos uma confluência das idéias fenomenológicas e existenciais, deslocando o estudo inicial da consciência para o estudo da intersubjetividade. Deste encontro, surge o pensamento fenomenológico-existencial que influenciou e influencia algumas formas de intervenção no âmbito da Psicologia.

Almeida (2006) aponta que as psicoterapias de base fenomenológico-existencial surgiram em contraste ao determinismo das terapias científico-naturalistas ou explicativos-causais. Como dito anteriormente, Hawkins \& Nestoros (1997) mapeiam três correntes principais em psicoterapia que se desenvolveram no século XX. As abordagens psicodinâmicas enfatizam a importância dos conflitos inconscientes, as abordagens comportamentais que entendem os comportamentos funcionais e disfuncionais como produtos de aprendizagem e abordagens humanistas/existenciais/fenomenológicas que enfatizam a liberdade de escolha. O Psicodrama e a Gestalt-Terapia se inserem nesta terceira força da Psicologia.
Pode-se perceber que as idéias existencialistas de liberdade e da capacidade do ser humano em superar a si mesmo e se modificar, estão presentes nas duas abordagens. A Gestalt-Terapia está interessada na recuperação do potencial criativo do sujeito. De acordo com Perls (1979): "Enquanto a teoria corrente se satisfaz com a recuperação como antídoto do empobrecimento provocado pela repressão, a Gestalt-Terapia ainda está mais interessada no descobrimento do potencial adormecido do indivíduo" (p. 142). Perls coloca como possibilidade a descoberta de aspectos novos do sujeito através da remoção de obstáculos.

A noção de liberdade, para o Psicodrama, está contemplada no conceito de espontaneidade que seria o estado produtor de todo processo criativo. A definição mais consagrada de espontaneidade seria "a capacidade de um indivíduo para enfrentar adequadamente cada nova situação ou dar novas respostas para situações antigas" (Moreno, 1975, p. 132). Quando Moreno refere-se à adequação da ação, ele quer dizer que o indivíduo espontâneo enfrenta novas situações utilizando-se livremente dos seus recursos - inteligência, memória, percepção, sentimentos, dentre outros - com um mínimo possível de entraves. Nos estados espontâneos o indivíduo experimenta um estado de autonomia e liberdade, um livre fluxo de sentimentos, em que sua ação está em sintonia com seus sentimentos e pensamentos. Naffah-Neto (1997) amplia o conceito de espontaneidade formulado por Moreno definindo esta como uma relação de compromisso entre sujeito e mundo, num esforço de recuperação de uma presença atuante e integrante da situação. Não seria uma simples relação de adequação e sim de compromisso com o mundo. $\mathrm{O}$ contraponto para a espontaneidade seria a conserva cultural que se refere a produtos culturais acabados ou atos finalizados. Aliás, espontaneidade e conserva cultural seriam etapas do processo de criação. A espontaneidade tem ligação com o momento da criação, com estados inacabados, imperfeitos e a conserva cultural seria o produto final de todo ato criativo. Moreno (1975) tecia corrosivas críticas à excessiva valorização das conservas culturais que vão desde artefatos da civilização até comportamentos estenotipados.

A Gestalt-Terapia também possui a pretensão de ruptura com os comportamentos estereotipados. Para tanto, adota como estratégia terapêutica a presentificação da experiência que seria a ênfase na experiência trazida pela pessoa no aqui-e-agora. A pessoa deve tomar posse de tudo o que a constitui e isto somente é possível no momento presente (Cardoso, 1999). Perls rompe com a interpretação do inconsciente e com as escavações do passado para deter-se em como os acontecimentos passados e projetos futuros são experimentados no presente (Miller, 1997). A GestaltTerapia também pretende promover nos seus clientes a recuperação da relação de compromisso com o mundo e a presença atuante na situação. A psicoterapia é um espaço de crescimento e não de adaptação (Cardoso, 1999). 
Perls (1979) traz uma importante contribuição na discussão sobre comportamentos repetitivos. Ele critica a premissa de que todos os hábitos seriam comportamentos cristalizados. Teríamos os hábitos que são comportamentos repetitivos, que fazem parte do eu e que têm a vantagem de economizar energia, como dirigir, por exemplo. Na formação organísmica de hábitos, os "bons hábitos são parte de um processo de crescimento, a realização de uma aptidão em potencial" (Perls, 1979, p. 85). Desta forma, estabelece-se uma diferença entre repetições compulsivas e formação organísmica de hábitos. Mesmo a repetição compulsiva não pode ser vista somente em termos de disfunção, mas como tentativa de lidar com situações inacabadas, como aponta Perls (1979): "as repetições são investimentos no sentido da complementação de uma gestalt de modo a libertar as energias para o crescimento e desenvolvimento" (p. 86). Esta visão das repetições como estando a serviço do crescimento organísmico não existe em Moreno. Este somente compreende as conservas culturais como comportamentos estereotipados que devem ser superados (Moreno, 1975). Há uma ênfase na recuperação dos estados espontâneos e nenhuma discussão sobre os possíveis aspectos positivos das conservas culturais.

Seguindo esta linha de raciocínio, a noção do ser humano como um organismo, da Gestalt-Terapia, poderia enriquecer a visão antropológica do psicodramatista. No Psicodrama, o ser humano é definido como um conglomerado de papéis (Gonçalves, 1988). Esta idéia do eu formado pelo desempenho dos papéis reflete a visão relacional do Psicodrama, mas carece de dinamismo que se encontra presente na visão do homem como organismo. Esta noção gestáltica descreve o homem como um ser de necessidades e a organização como princípio inerente ao organismo (Ribeiro, 1985). Quando há alguma necessidade, o organismo mobiliza suas forças para resolvê-la, para alcançar bem estar e finalizar a situação (Perls, 1977). As perturbações do equilíbrio organísmico constituem gestalten incompletas, o que força o organismo a encontrar maneiras de restaurar o equilíbrio. $\mathrm{O}$ crescimento se dá na fronteira de contato com o ambiente, buscando-se assimilar o que o organismo necessita e eliminar o dispensável, no sentido de manter um ponto de equilíbrio (Perls, Hefferline \& Goodman, 1997).

A oposição indivíduo e sociedade é um aspecto bastante discutido por Moreno e Perls. Perls (1977) aponta que a sociedade enfatiza o desenvolvimento intelectual e produz expectativas neuróticas de perfeição que levam o indivíduo a uma dissociação de sua natureza. O indivíduo se vê diante de um problema: ser aceito pela sociedade e integrar-se internamente (Perls, 1977). Tragicamente, o indivíduo aprende a ignorar os seus sentimentos, desejos e necessidades para responder a um conjunto de respostas fixas para ser aceito na sociedade. As reflexões de Ribeiro (1998) são oportunas: “como sermos diferentes numa sociedade coercitiva, controladora, mesmificadora e massificante" (p. 30)? Para este autor, o conflito entre sociedade e indivíduo é legítimo e merece ser trazido à luz, num mundo cheio de verdades prontas e acabadas.

Moreno (1975) discute que a espontaneidade é experimentada em graus maiores na infância. A criança defronta-se com inúmeras situações novas nas quais ela não dispõe de repertórios prontos de comportamentos, tendo, então, de recorrer à espontaneidade. Com o decorrer da socialização e a adoção de conservas culturais, o indivíduo vai perdendo a sua capacidade de responder ao mundo de maneira inovadora (Moreno, 1975). Portanto, para Moreno, a sociedade inibe a espontaneidade do indivíduo ao valorizar as conservas culturais. A relação ambígua de admiração e repulsa com relação à Freud também é um aspecto que aproximam Perls e Moreno. Perls comenta na sua autobiografia que não pode deixar de falar sobre Freud: "Freud, suas teorias, sua influência, são importantes demais pra mim. A minha admiração, perplexidade e vingatividade são muito fortes" (Perls, 1979, p. 61). A oposição às ideias freudianas contribuiu para 0 desenvolvimento da Gestalt-Terapia. A associação livre freudiana pode ser uma estratégia que dificulta a tomada de consciência gestáltica por valorizar o intelecto em detrimento das sensações e emoções.

Perls (1979, p. 74)) decepciona-se com o único encontro que teve com Freud. Neste encontro, de maneira excitada, Perls diz a Freud: "Vim da África do Sul para dar uma palestra e para vê-lo." Ao que responde Freud: "Bem, e quando você volta"? A frieza de Freud fez Perls declarar que esta era uma situação inacabada em sua vida. Moreno também teve um encontro com Freud que relatamos a seguir:

Doutor Freud, eu começo de onde você pára. Você vê as pessoas no ambiente artificial de seu consultório. $\mathrm{Eu}$ as vejo na rua e em suas casas, em seu ambiente natural. Você analisa seus sonhos. Eu procuro transmitir-lhes a importância de sonhar novamente" (Martín, 1996, p. 50).

Por um lado, Moreno elogiava Freud pelo fato de suas teorias terem surgido das experiências com os pacientes em análise. Por outro lado, Moreno pretendia superar o método psicanalítico individual e centrado na fala, propondo uma terapia de ação e em grupo.

Examinemos, neste momento, algumas possibilidades de integração entre conceitos e técnicas do Psicodrama e da Gestalt-Terapia. Pretendemos realizar trocas entre as abordagens para que esta ponte possa trazer enriquecer a prática de psicodramatistas e gestaltistas. É interessante observar que parece já ter havido alguma aproximação. Na introdução da autobiografia de Moreno, o filho dele, Jonathan Moreno diz: "Apesar de Moreno e Fritz Perls, que havia sido um devoto das sessões de Psicodrama em Nova York, terem discutido abertamente, Perls, sem se referir explicitamente a Moreno, reconheceu sua dívida ao 
Psicodrama em suas memórias.” (Moreno, 1997, p. 13). Jonathan Moreno narra os dissabores do pai que assistia a uma canibalização das ideias e técnicas psicodramáticas. Moreno se recusava a entrar no meio acadêmico, evitando associar-se a alguma universidade, por acreditar que este era um espaço conservador. Este fato coloca Moreno numa posição marginalizada no âmbito científico. Por outro lado, o seu carisma e criatividade influenciaram a cultura terapêutica da época, fazendo com que suas idéias fossem assimiladas, desacompanhadas do crédito a Moreno (Moreno, 1979). A Gestalt-Terapia também passou por uma fase de empobrecimento pelo despojamento do seu contexto teórico, na adoção de técnicas e slogans para a vida (Miller, 1997).

Nos escritos autobiográficos de Perls (1979) podemos localizar algumas possíveis influências recebidas do Psicodrama. Perls menciona a palavra "psicodrama” uma única vez, quando descreve o processo da retroflexão que seria uma inversão. A comunicação ao invés de ser dirigida ao outro vai para o próprio eu. Vejamos este trecho no qual descreve a cura para este padrão: "Faça aos outros, o que está fazendo a si próprio. Na verdade, é suficiente, até mesmo preciso que você faça essas coisas ruins aos outros, em fantasia, em psicodrama" (Perls, 1979, p. 248). Em outro trecho, Perls fornece exemplos sobre o trabalho dele com grupos. Diz que poderia começar pedindo aos membros do grupo que completassem a frase "Eu me ressinto". O próximo passo: "Explicite a sua exigência. $\mathrm{Ou}$ tenha um encontro em fantasia com essa pessoa até que o ressentimento esteja resolvido" (Perls, 1979, p. 221). Outra técnica utilizada por Perls é a cadeira vazia que deveria ser preenchida por pessoas e objetos fantasiosos promovendo interações destes com o sujeito. Pode ser que estas técnicas descritas acima tenham uma influência do Psicodrama. Se for verdade, parece que Perls valorizava a dramatização com representações de papéis como forma de lidar com o material emergente, com situações inacabadas e com sentimentos e sensações que surgem durante a sessão. Talvez alguns procedimentos psicodramáticos possam auxiliar na tomada de consciência ou awareness que é ponto central da Gestalt-Terapia (Perls, 1979). A concretização e objetivação de estados subjetivos, proposta do Psicodrama, pode promover o contato e a awareness, metas da Gestalt-Terapia. As duas propostas pretendem superar as abordagens analíticas, indo além de relatos verbais e intelectuais, valorizando a experiência e a vivência no aqui-e-agora clínico.

A Gestalt-Terapia e o Psicodrama valorizam, na prática clínica, a dimensão da ação como um recurso para ampliar a capacidade da pessoa de se envolver o mais completamente possível em determinada situação ou questão trazida. A Gestalt-Terapia utiliza-se dos experimentos que são recursos técnicos que visam à reconstituição da situação (Rodrigues, 2000). Nesta reconstituição, o cliente não somente relata situações, mas participa agindo fazendo com que esta ação estimule outros recursos como ex- pressão corporal, respiração, sentimentos e lembranças. De acordo com Rodrigues (2000), muitos clientes têm consciência das causas de questões que desejam mudar e, mesmo assim, não conseguem empreender as mudanças. Neste caso, o cliente profere um discurso racional que não o permite entrar em contato com ele mesmo. Para o autor o intuito do experimento, seria:

Ao invés de "falar sobre" - o que dispersa a pessoa com justificativas, avaliações, hábitos - propomos o "passar através”, ou seja, ficar na situação vivencial e descrever daquele ponto de vista, o que acontece com a pessoa, mantendo o foco sobre o tema prioritário, na medida em que este se demonstra. O experimento visa aumentar a capacidade do indivíduo de estar cônscio de seu momento existencial e emocional, fazendo contato com seu contexto de forma mais ampla (Rodrigues, 2000, p. 85).

A inclusão da dimensão da ação é uma tentativa de percepção de necessidades que não seriam percebidas somente na elaboração de relatos verbais para que o cliente possa buscar novas escolhas. É importante assinalar que é preciso ir além da descrição do que se vê na ação psicoterapêutica. Para Ribeiro (1985) a fenomenologia traz uma importante contribuição para a prática gestáltica que é a tentativa de clarificação da experiência humana. No entanto, é necessário ir além das aparências, exercitando a paciência diante do cliente que é um fenômeno de auto-revelação permanente e que esta revelação nunca se esgota (Ribeiro, 1985).

O Psicodrama tem como um de seus principais recursos a proposta da dramatização que representa a exteriorização e a concretização da subjetividade através da ação, da liberdade dada ao corpo. O objetivo é a ampliação do nível verbal de comunicação como forma de facilitar a emergência de respostas criativas e favorecer o desenvolvimento da flexibilidade. Segundo Cukier (1998), a dramatização fornece concretude a situações e afetos, que seriam meras ideias abstratas sem corporeidade para envolver o cliente. Para Moreno (1959), quando o protagonista desempenha os papéis de pessoas reais e imaginárias ocorre um efeito libertador. Para ele, o desenvolvimento de sintomas psicopatológicos se dá porque o sujeito investiu muita energia nas imagens do seu pai, mãe, esposa, filhos assim como nas ilusões e alucinações. Moreno descreve o potencial terapêutico da ação para o cliente: "Ele interioriza seu pai, sua mãe, sua amante, seu delírio e suas alucinações, e a energia que havia invertido morbidamente lhe é devolvida quando ele pode 'viver' realmente o papel de seu pai, seu patrão, seu amigo ou inimigo" (Moreno, 1959, p. 112). Na dramatização, o cliente tem a oportunidade de reordenar os elementos dispersos que sustentam os sintomas, adquirindo mais consciência das forças que limitam suas possibilidades (Vieira, 2009). 
Podemos perceber as semelhanças das abordagens no que tange à busca de recursos que ampliem a capacidade de expressão e tomada de consciência na prática clínica. Os objetivos são semelhantes, mas os caminhos se diferem. O Psicodrama enfatiza a representação de papéis, tanto de pessoas reais quanto de aspectos internos do cliente. A Gestalt-Terapia propõe a realização de experimentos para que o cliente explore o máximo possível a situação vivencial. $\mathrm{O}$ cliente é orientado a descrever o que acontece no presente e nada do que ele experimenta é descartado, sejam expressões corporais, sentimentos, respiração, lembranças. Uma possível integração entre estes recursos técnicos poderia ser a utilização de dramatizações nas quais o cliente representa papéis significativos somado ao uso de uma estratégia mais descritiva adotada pela Gestalt-Terapia. Poderia ser aproveitado o potencial terapêutico das dramatizações que auxilia na concretização e exteriorização de conteúdos internos aliado aos benefícios decorrentes da utilização da estratégia descritiva que permite a ampliação da percepção de aspectos para além da verbalização. Estas estratégias poderiam ser realizadas de forma concomitante. Enquanto o cliente dramatiza, o psicoterapeuta o orienta para a descrição do máximo possível de elementos presentes na situação. Estes conteúdos emergentes podem fomentar e ampliar a dramatização. Desta forma, poderia ser integrada a ação do Psicodrama com o 'experienciar' da Gestalt-Terapia.

\section{Considerações Finais}

O movimento integracionista está preocupado com aspectos que aumentem a eficácia dos atendimentos em psicoterapia, visto que hoje existe uma maior pressão por parte da sociedade - consumidores mais exigentes, planos de saúde - para que o psicólogo clínico ofereça um atendimento de qualidade.

A era Pós-Moderna em que nos encontramos, está marcada por uma desconfiança generalizada das chamadas metanarrativas religiosas, políticas, científicas e culturais que até recentemente determinaram a visão do mundo de grandes segmentos da população. As metanarrativas organizam axiomas e explicações dos fenômenos em grandes sistemas de verdade que possuem uma robusta coerência interna. Essa coerência os torna dificilmente questionáveis por quem pensa nos termos da metanarrativa. A experiência pós-moderna deixa cada vez menos espaço para esses sistemas. Coloca também em questão a possibilidade de que um sistema de psicoterapia detenha a verdade definitiva sobre o ser humano. Cabe mais na filosofia da era contemporânea supor que diferentes abordagens em psicoterapia podem contribuir com sua parcela para o entendimento do humano, não alcançando o esgotamento deste conhecimento. Desta forma, pode-se entrever que o interesse em inte- gração entre sistemas de psicoterapia pode aumentar num futuro próximo.

O diálogo entre Psicodrama e Gestalt-Terapia pode se revelar fecundo e originar um modelo enriquecido aproveitando-se de aspectos mais vantajosos de cada abordagem. Estas abordagens possuem raízes epistemológicas similares manifestadas na influência de conceitos e ideias do Existencialismo, da Fenomenologia e do Movimento Humanista, formando visões antropológicas semelhantes. Este terreno em comum pode facilitar a exploração conjunta de espaços disciplinares, fato que pode dar origem a um espaço interdisciplinar promissor. Podem-se articular conceitos e técnicas considerados mais vantajosos de cada abordagem que convidem à criação de novas formas de intervenções na prática clínica. Esta tentativa de articulação pode contribuir na superação de rivalidades metodológicas e mercadológicas entre o Psicodrama e a Gestalt-Terapia.

Para além da compatibilidade, poderia ser realizado um esforço integrativo entre as abordagens para que o produto resultante torne-se algo qualitativamente diferente do que a simples soma de conceitos e técnicas. Espera-se que o estudo possa auxiliar os psicoterapeutas na prática clínica fornecendo novas ferramentas de intervenção. Os clientes poderão ser beneficiados na medida em que o produto resultante pode levar a um aumento da eficácia terapêutica. Ainda esperamos contribuir para o movimento de integração no Brasil visto que este tema ainda é muito incipiente na comunidade de psicólogos clínicos brasileiros.

No presente trabalho, enfatizamos as aproximações entre as abordagens. Não temos a pretensão de ter esgotado o tema, há muito a ser realizado neste sentido. Esta ponte entre a Gestalt-Terapia e o Psicodrama pode ser ampliada, dada a riqueza de cada abordagem. Nesta aproximação, é importante assinalar que continuam sendo duas abordagens diferentes e que elas apresentam divergências e dessemelhanças em muitos aspectos. As aproximações entre a Gestalt-Terapia e o Psicodrama não precisam conduzir à criação de uma nova abordagem, dado que é importante que as duas abordagens possam continuar a existirem separadamente em face de suas riquezas. Outrossim, entendemos que estas aproximações podem contribuir para que gestaltistas e psicodramatistas se aprimorem como psicoterapeutas ao entrarem em contato com uma outra abordagem que é diferente e que, ao mesmo tempo, possui bases filosóficas em comum.

Por fim, nesta discussão, a Gestalt-Terapia e o Psicodrama podem amadurecer como abordagens. Uma consideração aberta e não dogmática de conceitos e técnicas - ora conciliáveis, ora complementares, ora antagônicos - facilitaria aos supervisores, docentes, clínicos e pesquisadores questionarem e aprofundarem seu próprio modelo clínico. E com esse questionamento interno, a abordagem só pode crescer e ganhar em profundidade. 


\section{Referências}

Almeida, W. C. (2006). Psicoterapia aberta. O método do psicodrama, a fenomenologia e a psicanálise. São Paulo: Ágora.

Cardoso, C. L. (1999). Aspectos filosóficos, teóricos e metodológicos da Gestalt-Terapia. Revista Psique, 9(14), 47-65.

Cukier, R. (1998). Sobrevivência Emocional. As dores da infância revividas no drama adulto. São Paulo: Ágora.

Eifert, G. H., \& Forsyth, J. P. (2005). Acceptance and Commitment Therapy for Anxiety Disorders. Oakland: New Harbringer.

Goldfried, M. R. (1982). On the History of Therapeutic Integration. Behavior Therapy, 13(1), 572-593.

Gonçalves, C. S. (1988). Lições de Psicodrama. Introdução ao Pensamento de J. L. Moreno. São Paulo: Ágora.

Gonçalves, I. C. \& Welling, H. (2001). Psicoterapeutas, Trabalho em Equipa e Integração em Psicoterapia. Psicologia, 15(2), 267-287.

Hawkins, P.J. \& Nestoros, J. N. (1997). Beyond the dogmas of conventional psychotherapy: the integration movement psychotherapy. Em P. J. Hawkins \& J. N. Nestoros, Psychotherapy: New Perspectives on Theory, Practice, and Research (pp. 01-68). Athens, Greece: Ellinika Grammata.

Kohlenberg, R. J. \& Tsai, M. (1987). Functional analytic psychotherapy. Em N. S. Jacobson (Org.), Psychotherapists in clinical practice: cognitive and behavioral perspectives (pp. 388-443). New York: Guilford.

Levy, L. (2000). Integrando diferenças. Possíveis caminhos da vivência terapêutica. São Paulo: Ágora.

Martin, E. G. (1996). A psicologia terapêutica de Moreno e a psicanálise de Freud. Em E. G. Martin, Psicologia do Encontro (pp. 47-72). São Paulo: Ágora.

Miller, M. V. (1997). Introdução. Em F. S. Perls, Gestalt-Terapi, (pp. 15-29). São Paulo: Summus.

Moreira, J. O., Romagnoli, R. C., \& Neves, E. O. (2007). O surgimento da clínica psicológica: da prática curativa aos dispositivos de promoção da saúde. Psicologia: Ciência e Profissão, 27(4), 608-621.

Moreno, J. L. (1959). Psicoterapia de Grupo e Psicodrama. São Paulo: Mestre Jou.

Moreno, J. L. (1975). Psicodrama. São Paulo: Cultrix.

Moreno, J. L. (1983). Fundamentos do Psicodrama. São Paulo: Summus.

Moreno, J. D. (1997). Introdução. Em J. L. Moreno, Autobiografia (pp. 5-17). São Paulo: Saraiva.

Naffah-Neto, A. (1997). Psicodrama: descolonizando o imaginário. São Paulo: Plexus Editora.

Norcross, J. C. (2010). The therapeutic relationship. Em B. L. Duncan, S. D. Miller, B. E. Wampold \& M. A. Hubble, The heart and soul of change. Delivering what really works (pp. 3568). Washington: American Psychological Association.
Perls, F. S. (1977). Isto é Gestalt. São Paulo: Summus.

Perls, F. S. (1979). Escarafunchando Fritz: dentro e fora da lata de lixo. São Paulo: Summus.

Perls, F. S., Hefferline, R., \& Goodman, P. (1997). Gestalt-Terapia. São Paulo: Summus.

Ribeiro, J. P. (1985). Gestalt-Terapia: refazendo um caminho. São Paulo: Summus.

Ribeiro, W. F. R. (1998). Existência - Essência. São Paulo: Summus.

Rodrigues, H. E. (2000). Introdução à Gestalt-Terapia. Conversando sobre os fundamentos da abordagem gestáltica. Petrópolis: Vozes.

Rogers, C. (1982). Tornar-se Pessoa. São Paulo: Martins Fontes.

Seixas, M. R. D. (1992). Sociodrama Familiar Sistêmico. São Paulo: ALEPH.

Sommers-Flanagan, J. (2006). Teorias de Aconselhamento e de Psicoterapia. Contexto e Prática: Habilidades, Estratégias e Técnicas. Rio de Janeiro: LTC.

Strieker, G. (1996), Psychotherapy Integration: An Assimilative, Psychodynamic Approach. Clinical Psychology: Science and Practice, 3(1), 47-58.

Vieira, É. D. (2009). Psicodrama: Introdução à Teoria, Prática e Pesquisa. Revista da Sociedade de Psicologia do Triângulo Mineiro, 13(1), 88-93.

Érico Douglas Vieira - Possui graduação em Psicologia pela Universidade Federal de Minas Gerais, Especialização em Psicodrama pelo Instituto Mineiro de Psicodrama Jacob Levy Moreno, Mestrado em Psicologia pela Pontifícia Universidade Católica de Minas Gerais. Atualmente é Doutorando em Psicologia pela Pontifícia Universidade Católica de Goiás, exercendo a Docência como Professor efetivo do curso de Psicologia da Universidade Federal de Goiás (Campus Jataí). Endereço Institucional: Universidade Federal de Goiás, Campus Avançado de Jataí. Rua Riachuelo - Centro - CEP: 75,804-020 - JataíGO. Email: ericopsi@yahoo.com.br

Luc Vandenberghe - Possui Graduação e Mestrado em Psicologia na Rijks Universiteit Gent, Doutorado em Psicologia pela Université de l'Etat à Liège, Bélgica. É Professor Adjunto do Programa de Pós-Graduação Stricto Sensu em Psicologia da Pontifícia Universidade Católica de Goiás. Endereço Institucional: Pontifícia Universidade Católica de Goiás, Centro de Ciências Humanas, Departamento de Psicologia. Av. Universitária, no 1410 - Setor Universitário - CEP: 74.000-000. Goiânia-GO. Email: luc.m.vandenberghe@gmail.com

Recebido em 30.05.11 Primeira Decisão Editorial em 10.08.11 Aceito em 02.09.11 